\title{
Etiology of Moldy Core, Core Browning, and Core Rot of Fuji Apple in China
}

L. L. Gao, State Key Laboratory of Crop Stress Biology in Arid Areas and College of Plant Protection, Q. Zhang**, College of Life Sciences, and X. Y. Sun, L. Jiang, R. Zhang, and G. Y. Sun, State Key Laboratory of Crop Stress Biology in Arid Areas and College of Plant Protection, Northwest A\&F University, Yangling, Shaanxi, 712100, P. R. China; Y. L. Zha, Agricultural Bureau of Xianyang, Xianyang City, Shaanxi Province, 712000, P. R. China; and Alan R. Biggs, Kearneysville Tree Fruit Research and Education Center, West Virginia University, Kearneysville 25430

\begin{abstract}
Gao, L. L., Zhang, Q., Sun, X. Y., Jiang, L., Zhang, R., Sun, G. Y., Zha, Y. L., and Biggs, A. R. 2013. Etiology of moldy core, core browning, and core rot of Fuji apple in China. Plant Dis. 97:510-516.

'Fuji' apple fruit were collected in Shaanxi Province, China, and 186 fungal isolates were obtained from the fruit core region. Fungi were isolated from fruit with symptomless core regions, as well as from the core regions of fruit showing browning, typical moldy core, or core rot. Based on phylogenetic and morphological analysis, all fungi were identified to species. Pathogenicity was determined by cutting apple fruit into halves and daubing spore suspensions containing $1 \times 10^{4}$ up to $1 \times 10^{8}$ spores $/ \mathrm{ml}$ on the carpel in the core region. Pathogenicity varied significantly among genera, with Alternaria and Cladosporium spp. causing core browning at lower spore concentrations and moldy

core at higher spore concentrations. Combinations of pathogens initiated more browning and moldy core than the pathogens applied alone. Epicoccum and Phoma spp. predominated in dry core rot, whereas primarily Trichothecium but also Fusarium and Penicillium spp. caused wet core rot. Core browning was introduced as a new type of core symptom, along with moldy core, dry core rot, and wet core rot. Alternaria alternata, A. tenuissima, A. arborescens, Cladosporium cladosporioides, and $C$. tenuissimum were the main pathogens causing core browning and moldy core.
\end{abstract}

Moldy core is an important disease of apple worldwide. It has been recorded in Australia, Canada, New Zealand, South Africa, The Netherlands, the United Kingdom, and the United States (28). It is characterized by the growth of mycelia within the locules, with or without penetration to the flesh immediately surrounding the core $(7,28)$. Moldy core of apple is undetectable until the fruit is cut open or consumed, potentially affecting consumer confidence (22). In one test in Australia, 5\% of stored 'Fuji' apple fruit exhibited moldy core (8). During late summer to early fall 1993 , moldy core was very common in Fuji apple in the San Joaquin Valley of California (10). In 2003, the incidence of 'Red Delicious' apple fruit infected with moldy core in some orchards of northern Israel was up to $40 \%$ (15).

Many studies have shown that moldy core is caused by a variety of fungi. In Oregon, the most common fungi associated with moldy core were Alternaria, Stemphylium, Cladosporium, Ulocladium, Epicoccum, Coniothyrium, and Pleospora spp. (28). Alternaria spp. were the most commonly isolated fungi associated with moldy core of 'Delicious' apple fruit in Ohio (7). Fungi that were associated with core rot of 'Starking' apple fruit in South Africa included Alternaria alternata, Pleospora herbarum, Coniothyrium sp., Penicillium funiculosum, $P$. expansum, $P$. ramulosum, and $P$. sp. (aff. dendriticum) $(3,35)$. During investigations in 2004 to 2006 in apple orchards in Slovenia, Fusarium avenaceum was identified as the causal agent of a wet apple core rot. Infections were associated with high amounts of mycotoxins, which may pose a risk for consumers of fresh or processed apple products $(26,27)$.

Corresponding author: G. Y. Sun, E-mail: sgy@nwsuaf.edu.cn

* The $\boldsymbol{e}$-Xtra logo stands for "electronic extra" and indicates that Figures 1 and 2 appear in color in the online edition.

$* *$ Co-first author.

Accepted for publication 24 September 2012.

http://dx.doi.org/10.1094/PDIS-01-12-0024-RE

(c) 2013 The American Phytopathological Society
Combrink et al. (4) indicated that core infection occurs progressively as fungal spores and bacteria become established on senescing blossoms after the full bloom stage of bud development. Little et al. (9) indicated that fungal spores may gain entry to the seed locules via the calycine sinus at any stage of fruit development. Snowdon (25) noted that the incidence of moldy core tended to increase following intensive spray programs to reduce other fungi.

Conditions of high relative humidity, mild temperatures, and tissue susceptibility are important factors that affect natural infection in orchards. Once inside the fruit, the pathogens are protected from contact fungicides and conditions for their continued growth are excellent $(6,11,18,19,29,30)$.

The accepted common name "moldy core" includes the typical moldy core symptom, as well as the more advanced core rot symptom (American Phytopathological Society Common Names of Plant Diseases). The term "moldy core" as used herein refers to all the symptom types associated with core infections although, later in the article, we show that different pathogens are involved in the different symptom groups.

Although much is known about moldy core in other countries, very few studies have been conducted in China, the world's largest apple-producing country. Fuji is the main apple cultivar in China, comprising approximately $70 \%$ of current production. It is essential to know whether moldy core of Fuji apple in China has an etiology similar to that in other countries or whether other organisms are involved. The objective of this study was to identify the pathogens associated with moldy core of Fuji apple in China and investigate their various roles in production of moldy core symptoms.

\section{Materials and Methods}

Isolation and identification of fungi. Samples were collected in 2008 and 2009 from trees of commercial orchards during the harvesting season; the trees were approximately 15 to 25 years old. Some fungicides were applied during the bloom period for management of moldy core, including carbendazim and polyoxin. During the 2 years, 440 Fuji apple fruit were collected from 13 different counties in Shaanxi Province of China (Table 1). Harvested fruit were stored at $4^{\circ} \mathrm{C}$ before the isolations were conducted. Apple fruit were rinsed under running tap water and then allowed to 
air dry. Whole fruit were disinfested with $70 \%$ ethanol. The fruit were then dissected along the longitudinal axis to permit examination of the core region. Sampling was conducted by direct removal of fungal mycelium (1). If the core appeared uninfected, nine tissue pieces were removed ( 1 to $2 \mathrm{~mm}$ ) using a sterile blade and consisted of three pieces each from flesh, carpel, and seed. Material sourced from apple cores was subsequently placed on potato dex- trose agar (PDA) in 90-mm plastic petri dishes. After incubation at $25^{\circ} \mathrm{C}$ in the dark for 7 days, cultures were examined visually, and mixed cultures were separated to single cultures using sterile transfer. All the isolated fungi were preserved in hemolysis tubes (15 by $100 \mathrm{~mm}$ ) with PDA and marked with a code number.

The fungal isolates were identified on the basis of morphology and molecular data. When morphology on PDA and internal tran-

Table 1. Identification, origin, and pathogenicity of some fungal isolates

Fungal species

Acremonium alternatum Link

Alternaria alternata (Fr.) Keissl.

Isolate code

\begin{tabular}{|c|c|c|}
\hline Origin & Pathogenicity $^{\mathbf{a}}$ & Symptom type \\
\hline Heyang & - & $\ldots$ \\
\hline Yangling & - & $\ldots$ \\
\hline Fufeng & + & Moldy core \\
\hline Luochuan & + & Moldy core \\
\hline Yangling & + & Moldy core \\
\hline Yangling & + & Browning \\
\hline Yangling & + & Browning \\
\hline Yangling & + & Browning \\
\hline Fuxian & - & $\ldots$ \\
\hline Yanan & - & $\ldots$ \\
\hline Baishui & + & Moldy core \\
\hline Dali & + & Moldy core \\
\hline Yangling & + & Moldy core \\
\hline Baishui & - & $\ldots$ \\
\hline Baishui & + & Wet core rot \\
\hline Yangling & - & $\ldots$ \\
\hline Yangling & - & $\ldots$ \\
\hline Baishui & + & Browning \\
\hline Baishui & + & Browning \\
\hline Liquan & + & Browning \\
\hline Baishui & + & Browning \\
\hline Heyang & + & Browning \\
\hline Huangling & + & Browning \\
\hline Yangling & + & Browning \\
\hline Baishui & + & Wet core rot \\
\hline Hancheng & + & Wet core rot \\
\hline Baishui & - & $\ldots$ \\
\hline Luochuan & + & Dry core rot \\
\hline Yangling & + & Dry core rot \\
\hline Baishui & - & $\ldots$ \\
\hline Baishui & - & $\ldots$ \\
\hline Baishui & - & $\ldots$ \\
\hline Yangling & + & Wet core rot \\
\hline Yangling & + & Wet core rot \\
\hline Baishui & + & Wet core rot \\
\hline Yangling & + & Wet core rot \\
\hline Yangling & + & Wet core rot \\
\hline Yangling & + & Wet core rot \\
\hline Luochuan & + & Wet core rot \\
\hline Luochuan & + & Wet core rot \\
\hline Yangling & - & $\ldots$ \\
\hline Baishui & - & $\ldots$ \\
\hline Yangling & - & $\ldots$ \\
\hline Jiangzhang & + & Wet core rot \\
\hline Baishui & + & Wet core rot \\
\hline Yanan & + & Wet core rot \\
\hline Baishui & + & Wet core rot \\
\hline Yangling & + & Wet core rot \\
\hline Baishui & + & Wet core rot \\
\hline Yangling & + & Wet core rot \\
\hline Tongchuan & + & Dry core rot \\
\hline Jiangzhang & + & Dry core rot \\
\hline Luochuan & + & Dry core rot \\
\hline Yangling & + & Dry core rot \\
\hline Baishui & + & Dry core rot \\
\hline Liquan & - & $\ldots$ \\
\hline Baishui & - & $\ldots$ \\
\hline Yangling & - & $\ldots$ \\
\hline Yangling & + & Wet core rot \\
\hline Yangling & + & Wet core rot \\
\hline Baishui & - & $\ldots$ \\
\hline Yangling & + & Wet core rot \\
\hline Yangling & + & Wet core rot \\
\hline
\end{tabular}

\begin{tabular}{|c|c|c|}
\hline Origin & Pathogenicity $^{a}$ & Symptom type \\
\hline Heyang & - & $\ldots$ \\
\hline Yangling & - & $\ldots$ \\
\hline Fufeng & + & Moldy core \\
\hline Luochuan & + & Moldy core \\
\hline Yangling & + & Moldy core \\
\hline Yangling & + & Browning \\
\hline Yangling & + & Browning \\
\hline Yangling & + & Browning \\
\hline Fuxian & - & $\ldots$ \\
\hline Yanan & - & $\ldots$ \\
\hline Baishui & + & Moldy core \\
\hline Dali & + & Moldy core \\
\hline Yangling & + & Moldy core \\
\hline Baishui & - & $\ldots$ \\
\hline Baishui & + & Wet core rot \\
\hline Yangling & - & $\ldots$ \\
\hline Yangling & - & $\ldots$ \\
\hline Baishui & + & Browning \\
\hline Baishui & + & Browning \\
\hline Liquan & + & Browning \\
\hline Baishui & + & Browning \\
\hline Heyang & + & Browning \\
\hline Huangling & + & Browning \\
\hline Yangling & + & Browning \\
\hline Baishui & + & Wet core rot \\
\hline Hancheng & + & Wet core rot \\
\hline Baishui & - & $\ldots$ \\
\hline Luochuan & + & Dry core rot \\
\hline Yangling & + & Dry core rot \\
\hline Baishui & - & $\ldots$ \\
\hline Baishui & - & $\ldots$ \\
\hline Baishui & - & $\ldots$ \\
\hline Yangling & + & Wet core rot \\
\hline Yangling & + & Wet core rot \\
\hline Baishui & + & Wet core rot \\
\hline Yangling & + & Wet core rot \\
\hline Yangling & + & Wet core rot \\
\hline Yangling & + & Wet core rot \\
\hline Luochuan & + & Wet core rot \\
\hline Luochuan & + & Wet core rot \\
\hline Yangling & - & $\ldots$ \\
\hline Baishui & - & $\ldots$ \\
\hline Yangling & - & $\ldots$ \\
\hline Jiangzhang & + & Wet core rot \\
\hline Baishui & + & Wet core rot \\
\hline Yanan & + & Wet core rot \\
\hline Baishui & + & Wet core rot \\
\hline Yangling & + & Wet core rot \\
\hline Baishui & + & Wet core rot \\
\hline Yangling & + & Wet core rot \\
\hline Tongchuan & + & Dry core rot \\
\hline Jiangzhang & + & Dry core rot \\
\hline Luochuan & + & Dry core rot \\
\hline Yangling & + & Dry core rot \\
\hline Baishui & + & Dry core rot \\
\hline Liquan & - & $\ldots$ \\
\hline Baishui & - & $\ldots$ \\
\hline Yangling & - & $\ldots$ \\
\hline Yangling & + & Wet core rot \\
\hline Yangling & + & Wet core rot \\
\hline Baishui & - & $\ldots$ \\
\hline Yangling & + & Wet core rot \\
\hline Yangling & + & Wet core rot \\
\hline
\end{tabular}

Symptom type

\section{A. arborescens E.G. Simmons}

GL0801

GL09603

GL09715

GL0625

GL4231

GL6273

GL4304

GL09614

A. infectoria E.G. Simmons

GL6155

GL5255

GL4233

GL0451

ZQ111521

GL0836

Aphanocladium aranearum (Petch) W. Gams

Botryosphaeria dothidea (Moug. ex Fr.) Ces. \& De Not

Chaetomium globosum Kunze ex Fr.

GL0812

GL0411

GL3301

Cladosporium cladosporioides (Fresen.) G.A. de Vries

C. tenuissimum Cooke

GL0839

ZQ241422

GL7315

GL0850

GL0849

GL0848

ZQ150821

Colletotrichum gloeosporioides complex

GL0852

GL0831

GL4301

Coniothyrium diplodiella (Speg.) Sacc.

Epicoccum nigrum Link

GL5254

GL3303

GL08362

GL4151

GL5161

E. vitis (Schwein.) Ellis \& Everh.

GL09304

GL3311

Fusarium equiseti (Corda) Sacc.

F. proliferatum (Matsush.) Nirenberg ex Gerlach \& Nirenberg

GL1222

GL8122

F. solani (Mart.) Sacc.

GL09415

GL4104

GL0844

GL8442

GL4120

GL0481

GL9142

Mucor circinelloides Tiegh.
Nigrospora oryzae (Berk. \& Broome) Petch

Penicillium chrysogenum Thom

$P$. expansum Link

GL09809

GL0822

GL0823

GL4121

$P$. paneum Frisvad

GL09420

P. viridicatum Westling

GL0832

GL0827

Phoma exigua Sacc.

Ph. glomerata (Corda) Wollenw. \& Hochapfel

GL0826

GL09806

GL0833

GL0461

GL71510

GL9725

GL8912

Rhizopus stolonifer (Ehrenb.) Vuill.

GL8921

Spencermartinsia viticola (A.J.L. Phillips \& J. Luque)

A.J.L. Phillips, A. Alves \& Crous

GL3314

GL09306

Trichoderma inhamatum Veerkamp \& W. Gams

Trichothecium roseum (Pers.) Link

GL0834

GL0800

GL0824

a Symbols: +, fungus can infect apple and apple shows symptoms; -, fungus can not infect apple, pathogenicity tested with spore suspensions of $1 \times 10^{6}$ spores $/ \mathrm{ml}$. 
scribed spacer (ITS) region parameters were insufficient to identify some species, more gene sequences and culture characteristics were used based on fungal groups. For Alternaria spp., isolates were identified according to sporulation patterns on potato carrot agar (PCA) under an alternating light-and-dark cycle consisting of $8 \mathrm{~h}$ of cool-white daylight followed by $16 \mathrm{~h}$ of darkness at $25^{\circ} \mathrm{C}$ for 4 to 7 days $(23,24)$. For species of Cladosporium, microscopic observations of the isolates were made from colonies cultivated on synthetic nutrient-poor agar (SNA) and characteristic colonies were cultivated on malt extract agar (MEA) and oatmeal agar (OA) for 14 days at $25^{\circ} \mathrm{C}$ in the dark (21). Partial gene sequences were determined as described by Crous et al. (5) and Schubert et al. (21) for actin (ACT) and translation elongation factor $1-\alpha$ (TEF). Isolates of Fusarium were identified based on cultural and macroconidial morphology on carnation leaf agar (CLA) at $25^{\circ} \mathrm{C}$ in the dark (12) in combination with DNA sequences of the $\beta$-tubulin gene (13). The identification of Penicillium isolates was achieved using morphological characteristics on Czapek yeast autolysate agar (CYA) at $25^{\circ} \mathrm{C}$ in the dark (14), in combination with DNA sequences of the $\beta$-tubulin gene (20). All sequences used in molecular identifications were submitted to GenBank (Table 2).

Genomic DNA was isolated from fungal mycelium grown on MEA using the UltraClean Microbial DNA Isolation Kit (Mo Bio
Laboratories, Inc.), according to the manufacturer's protocols. The gene sequences used for the phylogenetic analysis were aligned using the Clustal X program (34). Phylogenetic analysis was performed using PAUP 4.0 (32).

Type of symptoms. Harvested apple fruit showed varying symptoms during the isolation of fungi. To facilitate characterization, symptoms were separated into three types: browning, moldy core, and core rot (Fig. 1). Browning was characterized by brown carpel walls and no mycelial growth in the core. Moldy core was characterized by black to gray fungus growth over the seed and carpel walls, and the entire central portion of the core was often filled with mycelium. Core rot was characterized by white mycelia or pink conidia groups growing in the core region and flesh appearing necrotic (dry core rot or wet core rot). The occurrence of each type was noted and frequencies were determined.

Pathogenicity. For inoculations, freshly harvested Fuji apple fruit were sterilized with $70 \%$ ethanol and cut into halves along the longitudinal axis with a flame-sterilized knife. Fruit halves were inoculated without additional wounding, using sterile swabs to gently daub the spore suspension into the core region, away from the area injured by the original cut. Spores were harvested from cultures by adding a small amount of sterile distilled water to each dish and gently rubbing the sporulating mycelial mats with a bent

Table 2. Information on molecular identification of some fungal isolates

\begin{tabular}{|c|c|c|c|c|c|c|}
\hline Isolate code & $\begin{array}{l}\text { Gene } \\
\text { region }^{\mathrm{a}}\end{array}$ & $\begin{array}{c}\text { GenBank accession } \\
\text { number }\end{array}$ & $\begin{array}{l}\text { GenBank number of } \\
\text { reference isolate }\end{array}$ & $\begin{array}{l}\text { Sequence } \\
\text { length (bp) }\end{array}$ & $\begin{array}{c}\text { Identity } \\
(\%)\end{array}$ & Fungal species \\
\hline GL0801 & ITS & JX241639 & AY566992 & 518 & 100 & Acremonium alternatum \\
\hline GL4231 & ITS & JX241640 & AF397222 & 525 & 99 & Alternaria alternata \\
\hline GL6273 & ITS & JX241641 & AF397237 & 538 & 100 & A. arborescens \\
\hline GL5255 & ITS & JX241642 & AF397246 & 553 & 99 & A. infectoria \\
\hline GL0451 & ITS & JX241643 & AF397221 & 515 & 99 & A. tenuissima \\
\hline GL0836 & ITS & JX241644 & AJ292431 & 539 & 100 & Aphanocladium aranearum \\
\hline GL0812 & ITS & JX241645 & JF501225 & 433 & 99 & Botryosphaeria dothidea \\
\hline GL0411 & ITS & JX241646 & GU563374 & 532 & 99 & Chaetomium globosum \\
\hline \multirow[t]{3}{*}{ GL0839 } & ITS & JX241647 & HM148003 & 473 & 100 & Cladosporium cladosporioides \\
\hline & TEF & JX241672 & HM148280 & 205 & 99 & C. cladosporioides \\
\hline & $\mathrm{ACT}$ & JX241674 & HM148490 & 198 & 97 & C. cladosporioides \\
\hline \multirow[t]{3}{*}{ GL0848 } & ITS & JX241648 & HM148197 & 473 & 100 & C. tепиissimum \\
\hline & TEF & JX241673 & HM148442 & 222 & 97 & C. tenuissimum \\
\hline & ACT & JX241675 & HM148687 & 229 & 99 & C. tепиissimит \\
\hline GL0852 & ITS & JX241649 & AJ301988 & 510 & 99 & Colletotrichum gloeosporioides complex \\
\hline GL4301 & ITS & JX241650 & EU520203 & 517 & 100 & Coniothyrium diplodiella \\
\hline GL3303 & ITS & JX241651 & FJ426997 & 479 & 99 & Epicoccum nigrum \\
\hline GL08362 & ITS & JX241652 & AJ302460 & 520 & 99 & Eutypella caricae \\
\hline GL5161 & ITS & JX241653 & FJ790855 & 539 & 99 & E. vitis \\
\hline \multirow[t]{2}{*}{ GL09304 } & ITS & JX241654 & GQ505752 & 513 & 99 & Fusarium equiseti \\
\hline & $\beta$-tubulin & JX241676 & GQ915441 & 806 & 98 & F. equiseti \\
\hline \multirow[t]{2}{*}{ GL1222 } & ITS & JX241655 & AF291061 & 557 & 99 & F. proliferatum \\
\hline & $\beta$-tubulin & JX241677 & AF291055 & 844 & 99 & F. proliferatum \\
\hline \multirow[t]{2}{*}{ GL09415 } & ITS & JX241656 & AB551705 & 522 & 99 & F. solani \\
\hline & $\beta$-tubulin & JX241678 & AB587061 & 742 & 98 & F. solani \\
\hline \multirow[t]{2}{*}{ GL0844 } & ITS & JX241657 & HM068317 & 509 & 99 & F. tricinctum \\
\hline & $\beta$-tubulin & JX241679 & AB587078 & 839 & 99 & F. tricinctum \\
\hline GL4120 & ITS & JX241658 & DQ118991 & 615 & 99 & Mucor circinelloides \\
\hline GL9142 & ITS & JX241659 & DQ219433 & 494 & 99 & Nigrospora oryzae \\
\hline \multirow[t]{2}{*}{ GL09809 } & ITS & JX241660 & EF200101 & 525 & 99 & Penicillium chrysogenum \\
\hline & $\beta$-tubulin & JX241680 & EF198568 & 409 & 100 & P. chrysogenum \\
\hline \multirow[t]{2}{*}{ GL0823 } & ITS & JX241661 & DQ339547 & 562 & 99 & P. expansum \\
\hline & $\beta$-tubulin & JX241681 & FJ457084 & 526 & 99 & P. expansum \\
\hline \multirow[t]{2}{*}{ GL09420 } & ITS & JX241662 & HQ442346 & 550 & 99 & P. paneum \\
\hline & $\beta$-tubulin & JX241682 & AY674387 & 428 & 99 & P. paneum \\
\hline \multirow[t]{2}{*}{ GL0832 } & ITS & JX241663 & AF033477 & 561 & 99 & P. viridicatum \\
\hline & $\beta$-tubulin & JX241683 & FJ004441 & 459 & 99 & P. viridicatum \\
\hline GL0826 & ITS & JX241664 & AY787726 & 467 & 99 & Phoma exigua \\
\hline GL0833 & ITS & JX241665 & FJ427005 & 486 & 99 & Ph. glomerata \\
\hline GL71510 & ITS & JX241666 & FJ427061 & 534 & 99 & Ph. samarorum \\
\hline GL9725 & ITS & JX241667 & EF432292 & 562 & 97 & Phomopsis sp. \\
\hline GL8921 & ITS & JX241668 & AY625075 & 600 & 99 & Rhizopus stolonifer \\
\hline GL3314 & ITS & JX241669 & AY905555 & 474 & 99 & Spencermartinsia viticola \\
\hline GL0834 & ITS & JX241670 & DQ093708 & 546 & 99 & Trichoderma inhamatum \\
\hline GL0800 & ITS & JX241671 & EU552162 & 590 & 100 & Trichothecium roseum \\
\hline
\end{tabular}

${ }^{\text {a }}$ ACT $=$ actin; ITS $=$ internal transcribed spacer, and TEF = translation elongation factor $1-\alpha$. 
glass rod (18). The spore concentration was determined and adjusted with the aid of a hemacytometer to obtain a series of five suspensions, containing $1 \times 10^{4}$ to $1 \times 10^{8}$ spores $/ \mathrm{ml}$.

Each apple was inoculated with several isolates from every species and each isolate inoculation was repeated three times in each of the 2 years of study. The control fruit were treated similarly to the inoculated fruit but with sterile water instead of spore suspensions. After inoculation, fruit were placed on trays, covered with plastic wrap to maintain high humidity, and held at $25^{\circ} \mathrm{C}$ in the dark. Fruit were examined daily and types of symptom expression were recorded.

To understand the effects of combined species from the genera Alternaria and Cladosporium on symptom formation, fruit were inoculated with combined concentrations of two different species in pathogenicity tests, with each pathogen present at $1 \times 10^{4}$ to $1 \times$
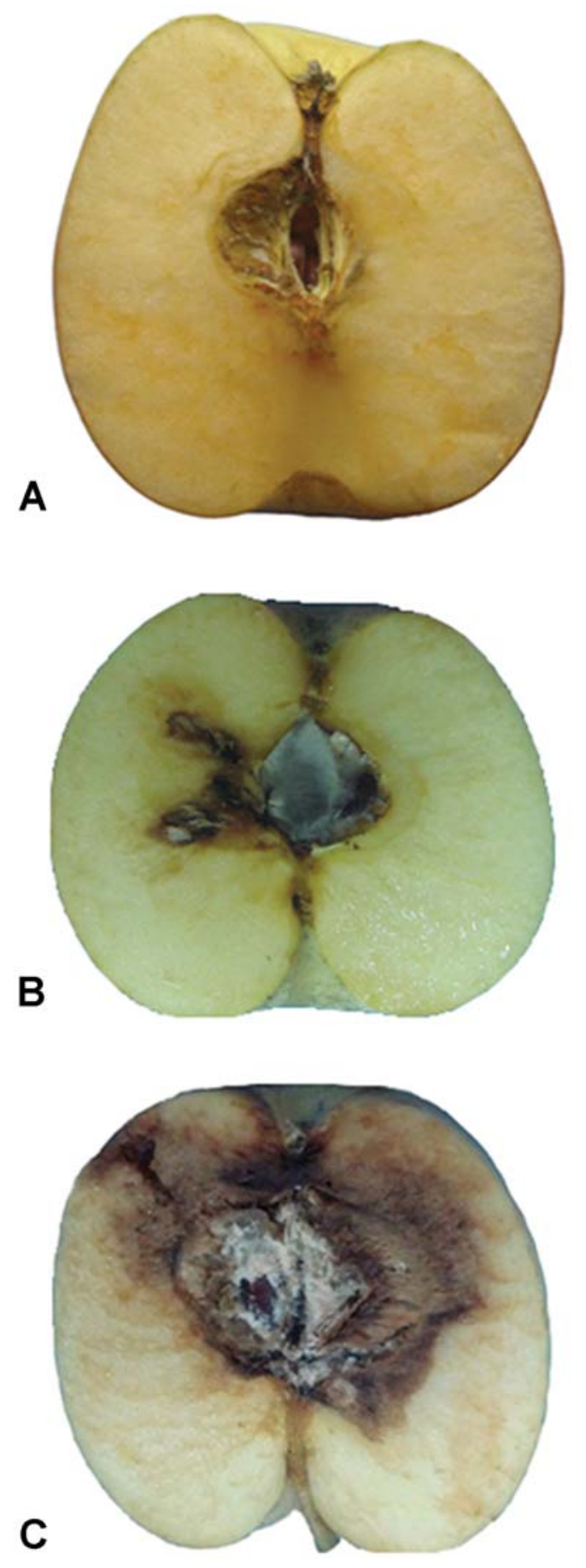

Fig. 1. Symptoms of three types: A, browning; B, moldy; and C, core rot.
$10^{6}$ spores $/ \mathrm{ml}$ (essentially $2 \times 10^{4}$ to $2 \times 10^{6}$ spores $/ \mathrm{ml}$ ). The inoculation method and assessment were the same as described above.

\section{Results}

Isolation and identification of fungi. The fungal genera Alternaria, Cladosporium, Epicoccum, Fusarium, Penicillium, Phoma, and Trichothecium were isolated more frequently than other fungi (fungi with isolation frequency above $1 \%$ are shown in Table 3). Some fungi appeared one or two times, including Botryosphaeria dothidea, Coniothyrium diplodiella, and Mucor circinelloides (data not shown).

Based on the combined phylogenetic and morphological analyses, all fungal isolates belonged to 33 species in 20 genera: Acremonium alternatum; Alternaria alternata, A. arborescens, A. infectoria, and A. tenuissima; Aphanocladium aranearum; $B$. dothidea; Chaetomium globosum; Cladosporium cladosporioides and C. tenuissimum; Colletotrichum gloeosporioides complex; Coniothyrium diplodiella; Epicoccum nigrum; Eutypella caricae and E. vitis; Fusarium equiseti, F. proliferatum, $F$. solani, and $F$. tricinctum; Mucor circinelloides; Nigrospora oryzae; Penicillium chrysogenum, $P$. expansum, $P$. paneum, and P. viridicatum; Phoma exigua, Ph. glomerata, and Ph. samarorum; Phomopsis sp.; Rhizopus stolonifer; Spencermartinsia viticola; Trichoderma inhamatum; and Trichothecium roseum (Table 2).

Type of symptoms. Three types of symptoms were observed on infected samples (Fig. 1). Browning occurred most frequently $(43.2 \%)$, with the occurrence rates of core rot and moldy core at 30.7 and $26.1 \%$, respectively.

Pathogen composition for the three symptom types was different (Fig. 2). In browning (Fig. 2A), the genera Alternaria and Cladosporium individually occurred in 24.3 and $8.8 \%$ of the apple fruit, respectively. These two genera appeared simultaneously in $43.7 \%$ of isolations, and also appeared with other fungi, including species of Epicoccum, Phoma, Penicillium, and Fusarium in $13.4 \%$ of isolations. In total, Alternaria and Cladosporium spp. could be isolated from 81.4 and $65.9 \%$ of diseased fruit, respectively, indicating that both Alternaria and Cladosporium spp. are the main pathogens associated with core browning.

For moldy core (Fig. 2B), the genera Alternaria and Cladosporium individually occurred in 34.7 and $14.4 \%$ of affected apple fruit, respectively. These two fungi appeared with other fungi, such as species of Fusarium, Penicillium, and Phoma in $41.0 \%$ of isolations. In total, Alternaria and Cladosporium spp. could be isolated from 75.7 and $55.5 \%$ of diseased fruit, respectively, indicating that both Alternaria and Cladosporium spp. are also the main pathogens associated with moldy core.

For core rot (Fig. 2C), the genus Trichothecium occurred in $24.7 \%$ of isolations and was mixed with species of Alternaria, Epicoccum, Fusarium, Penicillium, and Phoma in $28.1 \%$ of isolations. Thus, Trichothecium was the main pathogen associated with core rot and was found in $52.8 \%$ of isolations. Although the genera Penicillium, Epicoccum, Phoma, and Fusarium occurred alone $(6.7,3.9,3.4$, and $2.2 \%$, respectively) or in various combinations (18.4\%) in low frequency, altogether they amounted to about one-

Table 3. Isolation frequency of pathogenic fungi from different symptom types

\begin{tabular}{lccc}
\hline & \multicolumn{3}{c}{ Isolation frequency $(\%)^{\mathbf{a}}$} \\
\cline { 2 - 4 } Fungi & Browning & Moldy core & Core rot \\
\hline Alternaria spp. & 78.32 & 72.39 & 8.72 \\
Cladosporium spp. & 53.11 & 16.68 & 2.30 \\
Epicoccum nigrum & 4.76 & 2.20 & 13.59 \\
Fusarium spp. & 3.21 & 5.86 & 8.84 \\
Penicillium spp. & 1.59 & 4.11 & 16.25 \\
Phoma spp. & 3.72 & 7.73 & 15.13 \\
Trichothecium roseum & 2.82 & 1.63 & 52.77 \\
\hline
\end{tabular}

${ }^{\text {a }}$ Isolation frequency $=$ (number of apple fruit infected with fungi/total number of fruit of each type) $\times 100$. 
third of isolations (34.6\%) and, when combined with co-occurrences with Trichothecium (28.1\%), they amounted to $62.7 \%$ of the isolations. Therefore, even though the genus Trichothecium is a predominant pathogen in core rot isolations, other species of Penicillium, Epicoccum, Phoma, and Fusarium also contribute to the occurrence of core rot.

Species of Phoma, Epicoccum, and Penicillium could cause core rot (Table 1) but they also occurred in samples with browning, alone $(9.8 \%)$ or simultaneously with Alternaria and or Cladosporium spp. (13.4\%) (Fig. 2A). Although Alternaria and or Cladosporium spp. were the predominant organisms associated with both browning and moldy core, they also could be isolated,

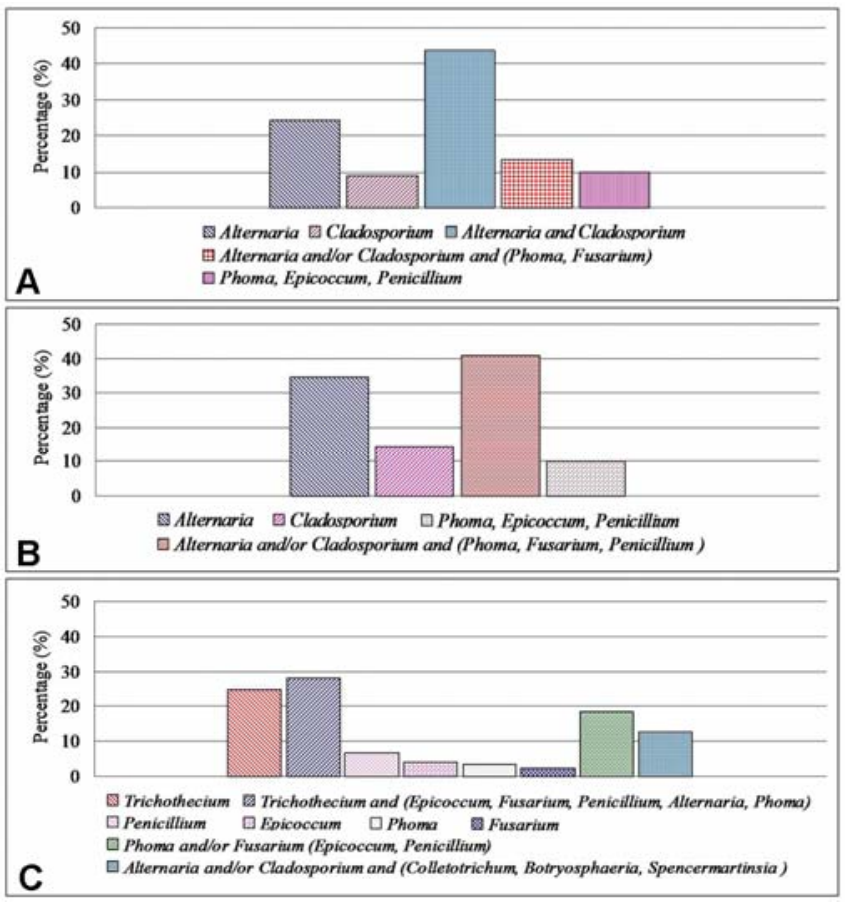

Fig. 2. Pathogen composition of the three symptom types: A, browning; B, moldy; and $\mathbf{C}$, core rot. although at much lower frequencies, from samples with core rot and co-occurring with Colletotrichum, Botryosphaeria, and Spencermartinsia spp. (12.6\%) (Fig. 2C).

When identified to species level, three pathogenic Alternaria spp. (Alternaria alternata, 48.8\%; A. tenuissima, 32.6\%; and A. arborescens, $18.6 \%$ ) and two Cladosporium spp. (Cladosporium cladosporioides, $48.8 \%$; and C. tenuissimum, $51.2 \%$ ) were present in a high ratio of isolations from diseased fruit, regardless of the symptom type.

Pathogenicity. On nonwounded apple halves, variation in symptom appearances of core browning, moldy core, and core rot were related to the fungal species utilized. At a spore concentration of 1 $\times 10^{6} \mathrm{spores} / \mathrm{ml}$, A. alternata and A. tenuissima caused the moldy core symptom, whereas $A$. arborescens, $C$. cladosporioides and $C$. tenuissimum caused the browning symptom. Fungi causing wet core rot included B. dothidea, Colletotrichum gloeosporioides complex, F. equiseti, F. proliferatum, F. tricinctum, Penicillium chrysogenum, $P$. expansum, $P$. paneum, $P$. viridicatum, Spencermartinsia viticola, and Trichothecium roseum. Dry core rot was caused by Epicoccum nigrum, Phoma exigua, Ph. glomerata, and Ph. samarorum (Table 1).

Inoculum concentration affected the symptom appearances with some of the Alternaria and Cladosporium spp. When a series of suspension concentrations was used in pathogenicity tests, it was found that the species A. alternata, A. arborescens, A. tenuissima, Cladosporium cladosporioides, and $C$. tenuissimum caused browning in relatively lower concentrations and moldy core under relatively higher spore concentrations (Table 4). For example, for $A$. alternata and A. tenuissima, browning occurred following inoculation with $1 \times 10^{5}$ spores $/ \mathrm{ml}$, whereas moldy core occurred following inoculation with $1 \times 10^{6}$ spores $/ \mathrm{ml}$. Furthermore, the lowest inoculum concentrations required for symptom formation varied among species (i.e., for Alternaria and Cladosporium spp., $1 \times 10^{5}$ spores $/ \mathrm{ml}$ and $1 \times 10^{6}$ spores $/ \mathrm{ml}$, respectively, were required to initiate symptoms). For $C$. tenuissimum, the higher inoculation concentration, $1 \times 10^{8}$ spores $/ \mathrm{ml}$, was needed to initiate moldy core symptoms.

Because an inoculum concentration of up to $1 \times 10^{8}$ spores $/ \mathrm{ml}$ seemed unreasonably high for an individual pathogen under natural conditions, we tested the effects of combined inoculum concentrations on symptom formation (Table 5). It was found that lower combined inoculum concentrations of individual pathogens com-

Table 4. Symptom types of Alternaria and Cladosporium spp. under different spore concentrations after inoculation

\begin{tabular}{|c|c|c|c|c|c|c|}
\hline \multirow[b]{2}{*}{ Fungal species } & \multirow[b]{2}{*}{ Isolate code } & \multicolumn{5}{|c|}{ Spore concentrations (spores $/ \mathbf{m l})^{\mathbf{a}}$} \\
\hline & & $1 \times 10^{4}$ & $1 \times 10^{5}$ & $1 \times 10^{6}$ & $1 \times 10^{7}$ & $1 \times 10^{8}$ \\
\hline Alternaria alternata & GL09715 & - & B & M & M & M \\
\hline A. tenuissima & ZQ111521 & - & $\mathrm{B}$ & M & M & M \\
\hline A. arborescens & GL09614 & - & $\mathrm{B}$ & $\mathrm{B}$ & M & M \\
\hline Cladosporium cladosporioides & ZQ241422 & - & - & B & M & M \\
\hline C. tenuissimum & ZQ150821 & - & - & B & B & M \\
\hline
\end{tabular}

${ }^{a}$ Symbols: $-=$ no infection observed, $\mathrm{B}=$ browning, and $\mathrm{M}=$ moldy core.

Table 5. Symptom types of Alternaria and Cladosporium spp. under different spore concentrations after combined inoculation

\begin{tabular}{|c|c|c|c|c|}
\hline \multirow[b]{2}{*}{ Combination } & \multirow[b]{2}{*}{ Isolate code } & \multicolumn{3}{|c|}{ Spore concentrations (spores/ml) ${ }^{\mathbf{a}}$} \\
\hline & & $1 \times 10^{4}$ & $1 \times 10^{5}$ & $1 \times 10^{6}$ \\
\hline Alternaria alternata + A. arborescens & GL09715 + GL09614 & - & B & M \\
\hline A. alternata + A. tenuissima & GL09715 + ZQ111521 & - & B & M \\
\hline A. arborescens + A. tenuissima & GL09614 + ZQ111521 & - & B & M \\
\hline A. alternata + Cladosporium cladosporioides & GL09715 + ZQ241422 & - & B & M \\
\hline A. alternata + C. tenuissimum & GL09715 + ZQ150821 & - & $\mathrm{B}$ & M \\
\hline A. arborescens $+C$. cladosporioides & GL09614 + ZQ241422 & - & B & M \\
\hline A. arborescens + C. tenuissimum & GL09614 + ZQ150821 & - & B & M \\
\hline A. tenuissima $+C$. cladosporioides & ZQ111521 + ZQ241422 & - & B & M \\
\hline A. tenuissima $+C$. tenuissimum & ZQ111521 + ZQ150821 & - & B & M \\
\hline C. cladosporioides + C. tenuissimum & ZQ241422 + ZQ150821 & - & $\mathrm{B}$ & M \\
\hline
\end{tabular}

a Symbols: $-=$ no infection observed, $\mathrm{B}=$ browning, and $\mathrm{M}=$ moldy core. 
bined with a second organism also initiated browning and moldy core symptom formation. For A. arborescens, $C$. cladosporioides, and $C$. tenuissimum, moldy core occurred when combined by inoculation with $1 \times 10^{6}$ spores/ml (Table 5), but only browning appeared when inoculated separately under the same concentrations (Table 4). For C. cladosporioides and C. tenuissimum, browning occurred when combined by inoculation with $1 \times 10^{5}$ spores $/ \mathrm{ml}$ (Table 5) but no symptoms formed when inoculated separately under the same concentrations (Table 4). The control fruit did not show any symptoms in all of the experiments described above.

\section{Discussion}

The symptoms of moldy core mentioned in various studies are generally inconsistent in the literature. Ellis and Barrat (7) indicated that moldy core was characterized by the growth of mycelia within the locules, with or without penetration into the mesoderm, and may become invasive and lead to a slow, dry rot confined to the flesh immediately surrounding the core. However, Archer pointed out that, if the mycelia penetrated into flesh and caused rot of flesh, these symptoms belonged to core rot rather than moldy core (1). In this article, moldy core/core rot included all these symptoms and was subdivided into three types. The browning type was not the early symptom of moldy core; rather, it could be found from harvest through 3 months of refrigerated storage. Therefore, we have described core browning as a new individual symptom type, along with moldy core and wet and dry core rot. Sometimes, moldy core and core rot had some similar symptoms (i.e., flesh was necrotic); therefore, if the core region was filled by mycelia and the flesh was rotted but the core was not rotted, we divided this type into moldy core rather than core rot. In nature, we could find the moldy core symptom commonly but this symptom occurred just under a higher spore concentration in our inoculation experiments. It is proposed that the moldy core symptom can only be caused by sufficiently high inocula of one pathogen or combined pathogens at lower inoculum levels. The core rot symptom could separate into two types in the orchard: dry core rot and wet core rot. Wet core rot, mainly caused by Trichothecium roseum, Fusarium equiseti, $F$. proliferatum, $F$. tricinctum, Penicillium chrysogenum, $P$. expansum, $P$. paneum, and $P$. viridicatum, appeared more frequently than dry core rot, mainly caused by Epicoccum nigrum, Phoma exigua, Ph. glomerata, and Ph. samarorum; and this phenomenon was also demonstrated in the pathogenicity experiment. Because we didn't specifically study the pathogenic composition of these two types of core rot, additional research on the conditions that favor their development is needed.

The method of inoculation used in previous research involved injecting a spore suspension into the core region of apple fruit (10). The problem with this method is that before inoculation, it is difficult to know whether fruit were healthy or not. The advantages of the method we used could ensure that fruit were healthy before inoculation and the pathogenic progress of fungi could be observed daily without destructive sampling. Because inoculum concentration affects symptom development and the type of symptom, different inoculation concentrations are needed for successful assessments of moldy core pathogenesis. Results from this study suggest that inoculation concentrations from $1 \times 10^{4}$ to approximately $1 \times 10^{8}$ spores $/ \mathrm{ml}$ should be used.

Management of moldy core/core rot relies on the use of fungicides applied during the bloom period, although their effectiveness varies due to weather conditions and other unknown factors. Worldwide, fungicides used in recent years include boscalid; captan; polyoxin B; potassium phosphate; and steroidal saponine; the demethylation inhibitor fungicides difenoconazole and bromuconazole; and the strobilurins pyraclostrobin, kresoxim methy1, azoxystrobin, and trifloxystrobin. Most of these fungicides have been reported to be effective against $A$. alternata $(2,15,16,17,18)$. In this study, although Alternaria spp. could be isolated from samples with core browning $(81.4 \%)$ and moldy core $(75.5 \%)$, Cladosporium spp. could be isolated in high proportions as well (65.9 and 55.5\%, respectively); therefore, Cladosporium spp. should be included as primary causal agents of core browning and moldy core. For core rot, $T$. roseum was the main pathogen recovered (about $52.8 \%$ of isolations), and species of Penicillium, Epicoccum, Phoma, and Fusarium occurred alone or co-occurred with $T$. roseum ( $62.7 \%$ of the isolations). These results showed that the core browning, moldy core, and core rot pathogens were a highly diverse fungal complex and the role of any particular species could not be overemphasized. We suggest that most of the pathogens should be examined when conducting a preliminary screening of fungicides.

Many genera, including Alternaria, Botryosphaeria, Botrytis, Candida, Cladosporium, Coniothyrium, Epicoccum, Fusarium, Gloeosporium, Mucor, Penicillium, Pestalotia, Phoma, Pleospora, Sporathrix, Stemphylium, and Ulocladium, were reported as pathogens associated with moldy core/core rot $(3,7,28,31,33,35)$. We found that fungi in 10 genera (Alternaria, Botryosphaeria, Cladosporium, Colletotrichum, Epicoccum, Fusarium, Penicillium, Phoma, Spencermartinsia, and Trichothecium) could cause browning, moldy core, or core rot symptoms in China, and identified them to species level. In our study, $C$. cladosporioides and $C$. tenuissimum are reported for the first time to cause moldy core. The species B. dothidea, $F$. equiseti, $F$. proliferatum, $F$. solani, $F$. tricinctum, $P$. chrysogenum, $P$. paneum, $P$. viridicatum, and $S$. viticola were found for the first time to cause wet core rot. The species E. nigrum, Ph. exigua, $P$ h. glomerata, and $P h$. samarorum were found for the first time to cause dry core rot. In China, $T$. roseum was a main pathogen of core rot but has not been a reported in other regions.

We identified the fungi to species level, because this may prove useful for choosing an effective fungicide. Future work will examine regional disease incidence, annual variation in the pathogen complex, and the management of moldy core/core rot.

\section{Acknowledgments}

This work was supported by National Natural Science Foundation of China ( 31170015 and 31171797), the 111 Project from Education Ministry of China (B07049), Top Talent Project of Northwest A\&F University, and the earmarked fund for Modern Agro-industry Technology Research System (nycytx-08-0404). We thank two anonymous reviewers for their constructive comments.

\section{Literature Cited}

1. Archer, C. 2002. The use of honeybees as a transfer vector for core rot in apples. Publ. No. 02/046, Project No. TAR-1A. Rural Industries Research and Development Corporation. Barton, Kingston, Australia.

2. Biggs, A. R., Ingle, M., and Solihati, W. D. 1993. Control of Alternaria infection of fruit of apple cultivar Nittany with calcium chloride and fungicides. Plant Dis. 77:976-980.

3. Combrink, J. C., Kotzl, J. M., Wehner, F. C., and Grobbelaar, C. J. 1985. Fungi associated with core rot of Starking apples in South Africa. Phytophylactica 17:81-83.

4. Combrink, J. C., Visagie, T. R., and Grobbelaar, C. 1984. Variation in the incidence and occurrence in different production areas of core rot in Starking apples. Deciduous Fruit Grow. 34:88-89.

5. Crous, P. W., Slippers, B., Wingfield, M. J., Rheeder, J., Marasas, W. F. O., Phillips, A. J. L., Alves, A., Burgess, T., Barber, P., and Groenewald, J. Z. 2006. Phylogenetic lineages in the Botryosphaeriaceae. Stud. Mycol. 55:235-253.

6. De Kock, S. L., Visagie, T. R., and Combrink, J. C. 1991. Control of core rot in Starking apples. Deciduous Fruit Grow. 41:20-22.

7. Ellis, M. A., and Barrat, J. G. 1983. Colonization of Delicious apple fruits by Alternaria spp. and effect of fungicide sprays on moldy-core. Plant Dis. 67:50-152.

8. Kupferman, E. M. 1992. Maturity and storage of apple varieties new to Washington State. Tree Fruit Postharvest J. 3:9-15.

9. Little, C. R., and Holmes, R. J. 2000. Storage Technology for Apples and Pears. Department of Natural Resources and Environment, Knoxfield, Victoria, Australia.

10. Michailides, T. J., Morgan, D. P., Mitchum, E., and Crisosto, C. H. 1994. Occurrence of moldy core and core rot of Fuji apple in California. KAC Plant Prot. Q. 3:5-7.

11. Miller, P. M. 1959. Open calyx tubes as a factor contributing to carpel discoloration and decay of apples. Phytopathology 49:520-523.

12. Nelson, P. E., Toussoun, T. A., and Marassas, W. F. O. 1983. Fusarium Species: An Illustrated Manual for Identification. The Pennsylvania State University, University Park.

13. O'Donnell, K., and Cigelnik, E. 1997. Two divergent intragenomic rDNA ITS2 types within a monophyletic lineage of the fungus Fusarium are non- 
orthologous. Mol. Phylogenet. Evol. 7:103-116.

14. Pitt, J. I. 1979. The Genus Penicillium and its Teleomorphic States Eupenicillium and Talaromyces. Academic Press, London.

15. Reuveni, M. 2006. Inhibition of germination and growth of Alternaria alternata and mouldy-core development in Red Delicious apple fruit by bromuconazole and sygnum. Crop Prot. 25:253-258.

16. Reuveni, M., Sheglov, D., and Cohen, Y. 2003. Control of moldy-core decay in apple fruits by $\beta$-aminobutyric acids and potassium phosphites. Plant Dis. 87:933-936.

17. Reuveni, M., Sheglov, N., Eshel, D., Prusky, D., and Ben-Arie, R. 2006. Virulence and the production of endo-1,4- $\beta$-glucanase by isolates of Alternaria alternata involved in the moldy-core disease of apples. J. Phytopathol. 155:50-55.

18. Reuveni, M., Sheglov, D., Sheglov, N., Ben-Arie, R., and Prusky, D. 2002. Sensitivity of Red Delicious apple fruit at various phenologic stages to infection by Alternaria alternata and moldy-core control. Eur. J. Plant Pathol. 108:421-427.

19. Roco, A., and Perez, L. M. 2001. In vitro biocontrol activity of Trichoderma harzianum on Alternaria alternata in the presence of growth regulators. Electron. J. Biotechnol. 4:68-73.

20. Samson, R. A., Seifert, K. A., Kuijpers, A. F. A., Houbraken, J. A. M. P., and Frisvad, J. C. 2004. Phylogenetic analysis of Penicillium subgenus Penicillium using partial $\beta$-tubulin sequences. Mycol. Res. 49:175-200.

21. Schubert, K., Groenewald, J. Z., Braun, U., Dijksterhuis, J., Starink, M. S., Hill, C. F., Zalar, P., de Hoog, G. S., and Crous, P. W. 2007. Biodiversity in the Cladosporium herbarum complex (Davidiellaceae, Capnodiales), with standardisation of methods for Cladosporium taxonomy and diagnostics. Stud. Mycol. 58:105-156.

22. Shenderey, C., Shmulevich, I., Alchanatis, V., Egozi, H., Hoffman A., Ostrovsky, V., Lurie, S., Ben-Arie, R., and Schmilovitch Z. 2010. NIRS detection of moldy core in apples. Food Bioprocess Technol. 3:79-86.

23. Simmons, E. G. 1992. Alternaria taxonomy: current status, viewpoint, challenge. Pages 1-35 in: In Alternaria: Biology, Plant Disease and Metabo- lites. J. Chelkowdki and A. Visconti, eds. Elsevier, Amsterdam.

24. Simmons, E. G., and Roberts, R. G. 1993. Alternaria themes and variations (73). Mycotaxon 48:109-140.

25. Snowdon, A. L. 1991. A colour atlas of post harvest diseases and disorders of fruit and vegetables. In: General Introduction and Fruits, Vol. 1. A. L. Snowdon, ed. Wolfe Publishing, London.

26. Sørensen, J. L., Nielsen, K. F., and Thrane, U. 2007. Analysis of moniliformin in maize plants using hydrophilic interaction chromatography. J. Agric. Food Chem. 55:9764-9768.

27. Sørensen, J. L., Phipps, R. K., Nielsen, K. F., Schroers H. J., Frank, J., and Thrane, U. 2009. Analysis of Fusarium avenaceum metabolites produced during wet apple core rot. J. Agric. Food Chem. 57:1632-1639.

28. Spotts, R. A. 1990. Moldy core and core rot. Pages 29-30 in: Compendium of Apple and Pear Diseases. A. L. Jones and H. S. Aldwinckle, eds. American Phytopathological Society, St. Paul, MN.

29. Spotts, R. A., and Cervantes, L. A. 1992. Effect of ozonated water on postharvest pathogens of pear in laboratory and packinghouse tests. Plant Dis. 76:256-259.

30. Spotts, R. A., Cervantes, L. A., and Mielke, E. A. 1999. Variability in postharvest decay among apple cultivars. Plant Dis. 83:1051-1054.

31. Spotts, R. A., Holmes, R. J., and Washington, W. S. 1988. Factors affecting wet core rot of apples. Australas. Plant Pathol. 17:53-57

32. Swofford, D. L. 2002. PAUP* Phylogenetic Analysis Using Parsimony (and other methods), version 4.0. Sinauer, Sunderland, MA.

33. Taylor, J. 1955. Apple black rot in Georgia and its control. Phytopathology. 45:392-398.

34. Thompson, J. D., Gibson, T.J., Plewniak, F., Jeanmougin, F., and Higgins, D. G. 1997. The CLUSTAL X windows interface: flexible strategies for multiple sequence alignment aided by quality analysis tools. Nucleic Acids Res. 25:4876-4882.

35. van der Walt, L., Spotts, R. A., Visagie, C. M., Jacobs, K., Smit, F. J., and McLeod, A. 2010. Penicillium species associated with preharvest wet core rot in South Africa and their pathogenicity on apple. Plant Dis. 94:666-675. 